\title{
La función de la escritura en Lacan
}

\section{The function of writing in Lacan}

\author{
Ruben CARMINE FASOLINO \\ Universidad Complutense de Madrid \\ virtualruben@hotmail.com
}

Recibido: 03/05/2011

Aceptado: 20/06/2011

\section{Resumen}

Este estudio quiere ser un modo de introducir y dilucidar la compleja relación del psicoanalista francés Jacques Lacan con la escritura a través de su teoría de la autonomía del significante. Para ello la atención se centrará, principalmente pero no solamente, en unas lecciones del Seminario XVIII -año 1971-titulado "De un discurso que no fuera del semblante", seminario que se coloca en una época, histórica y personal, de fundamental importancia para su autor: los cambios políticos y sociales no dejan indiferente al psicoanalista francés que el año antes, 1970, se distingue, con un gesto crítico, de sí mismo -se podrá hablar después de este año de un Lacan I y de un Lacan II-, pero también de Freud en tanto que nombre propio y padre del psicoanálisis. Todo este movimiento lleva el título de un importante seminario: "El reverso del psicoanálisis", donde se prefigura la noción fundamental de discurso como estructura que constituye la matriz de cualquier acto en el que se toma la palabra, una palabra que está rigurosamente constreñida por una estructura que la precede y que son los tipos de enunciación que Lacan llama "discursos". Los restringirá a cuatro: el del amo, el del histérico, el del analista y el discurso de la universidad. Después del importante "Seminario sobre La carta robada" de 1956 y del escrito de 1957 "La instancia de la letra en el inconsciente", Lacan volverá, catorce años después, sobre el tema de la escritura en una época marcada por el cambio: en la sociedad y en su misma doctrina.

Palabras clave: escritura, discurso, estructura, significante, amo, histérico, analista, universidad. 


\begin{abstract}
This essay pretends to introduce and elucidate the complex relationship of French psychoanalyst Jacques Lacan with writing through his theory of the autonomy of the signifier. To reach this goal I will focus primarily, but not only, in some lessons of the Seminar XVIII-year 1971 - titled "On a Discourse That Would Not Be Semblance'. This seminar is located in a historical moment of fundamental importance to its author: political and social changes do not leave indifferent the French psychoanalyst, who the precedent year, 1970, stands with a critical sign of himself; after this year we can distinguish between Lacan I and Lacan II, and we can also talk about Freud, in a personal way and as founder of psychoanalysis. This movement bears the title of an important workshop: 'The other side of psychoanalysis', which shapes the fundamental notion of discourse as a structure that sets the nucleus of any act in which words are involved, words that are severely constrained of a structure that precedes it and that are called by Lacan 'discourses' .He will resume them in four types: the master, the hysteric, the analyst and the discourse of the university. After the important seminar on The Purloined Letter" of 1956 and the text of 1957 «The Instance of the Letter in the Unconscious», Lacan will return, after fourteen years, to the argument of writing in a period marked by change: in society and in his doctrine.
\end{abstract}

Keywords: writing, discourse, structure, signifier, master, hysterical, analyst, university.

\title{
Sumario
}

1. Introducción

2. Lacan I, Lacan II

3. La función de la escritura

\section{Introducción}

Lacan, que funcionará de ahora en adelante como nombre propio, designa con la palabra "letra" el soporte material que el discurso concreto toma del lenguaje. E1 escrito, por tanto, se distingue por una prevalencia del texto. Corre el año 1957, el año del escrito "La instancia de la letra en el inconsciente o la razón después de Freud". Es también el tiempo de otro escrito clave para Lacan: "Función y campo de la palabra y del lenguaje en psicoanálisis", el informe de Roma -pronunciado los días 26 y 27 de septiembre de 1953-que marcó el debut público de la enseñanza 
lacaniana. En medio de estas fechas se sitúa el famoso "Seminario sobre La carta robada" de 1956. Son los años del "regreso" a Freud.

Del notable material que se sacará de estos escritos -y que en este lugar no tendremos tiempo de analizar como se merece- destacan, en particular, la lectura que Lacan hace del automatismo de repetición (o compulsión de repetición) (Wiederholungszwang) que encuentra su principio en la cadena significante, cuya ley rige los efectos psicoanalíticos determinados por el sujeto: la forclusión o preclusión (Verwerfung), la represión (Verdrängung) y la denegación o renegación (Verneinung). Se añadirá que estos efectos siguen servilmente el desplazamiento (Entstellung) del significante. Como no dejará de repetir una y otra vez Lacan, es el orden simbólico lo que constituye el sujeto, en cuanto determinado por el recorrido de un significante, y querrá demostrarlo con el seminario sobre el cuento de Poe, en tanto la compulsión a la repetición siempre se realiza en relación al mismo significante.

La insistencia en el significante -que Lacan toma del Curso de lingüistica general de Ferdinand de Saussure en lo que se refiere al signo lingüístico como la constitución de dos partes denominadas la una "significante" y la otra "significado"-, quiere demostrar que el inconsciente está estructurado como un lenguaje y que en la cadena significante se refleja no una cadena de significados, sino el sometimiento del sujeto a la determinación simbólica. ${ }^{1}$

El sometimiento al significante -que no hay que confundir apresuradamente con el sometimiento al Logos o a la palabra inspirada (volveremos sobre este asunto en la tercera parte del artículo) - se hace patente desde la perspectiva analítica la cual promueve una distinción fundamental: el yo del sujeto no es idéntico a la persona que habla.

Antes de continuar habrá que fijar lo que Lacan, partiendo de la base saussuriana, entiende por "significante". Como hemos afirmado más arriba, en la terminología de Saussure el significado y el significante son las componentes del signo, como apunta el autor ginebrino ${ }^{2}$. Recordaremos de paso que ya los Estoicos distinguían

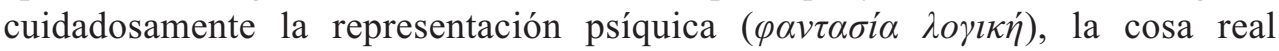

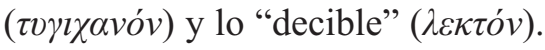

\footnotetext{
${ }^{1}$ Lacan J., Escritos I, Buenos Aires, Siglo Veintiuno Editores, 2008, p. 40. Con palabras del mismo Lacan: "Si lo que Freud descubrió y redescubre de manera cada vez más abrupta tiene un sentido, es que el desplazamiento del significante determina a los sujetos en sus actos, en su destino, en sus rechazos, en sus cegueras, en sus éxitos y en su suerte, a despecho de sus dotes innatas y de su logro social, sin consideración del carácter o el sexo, y que de buena o mala gana seguirá al tren del significante como armas y bagajes, todo lo dado de lo psicológico".

2 "Todo estudio de una lengua como sistema, es decir, de una morfología, significa estudiar el uso de las formas o la representación de las ideas, como se prefiera. Lo que es erróneo es pensar que existen formas en parte alguna (que existan por sí mismas fuera de su uso) o que existan ideas en parte alguna (que existan por sí mismas fuera de su representación)". Saussure F., Escritos sobre lingüística general, Barcelona, Editorial Gedisa, 2004, p. 36.
} 
En Lacan, por otra parte, el significado y el significante coinciden en la que puede ser denominada una "relación fluctuante" y no se encuentran más que en algunos puntos de anclaje. El significado es básicamente reprimido y es el significante lo que determina y representa, tanto a nivel consciente como inconsciente, el sujeto. Ya en Freud, antes que en Lacan, se puede apreciar que el psicoanálisis es una experiencia de lenguaje, de palabra y que las primeras pacientes histéricas son curadas a través de la verbalización, a saber, pueden por fin decir lo que nunca pudieron enunciar. ${ }^{3}$

Para profundizar un poco más en el método psicoanalítico, proponemos la siguiente cita tomada del Diccionario del Psicoanálisis dirigido por R. Chemana y B. Vandermersch:

Desde el momento en que el método psicoanalítico, en efecto, pasa a tomar en cuenta la actualización de los conflictos latentes más que la rememoración directa de los recuerdos patógenos, esto lo lleva a interesarse particularmente en las formaciones del inconsciente, en las que estos conflictos se encuentran representados. Y estos están regulados por encadenamientos rigurosos de lenguaje. Es el caso del lapsus, del olvido y, en general, del acto fallido, que puede enunciar un deseo de manera alusiva, metafórica o metonímica [...] Por último, es el caso del sueño, cuyo relato se lee como un texto complejo, que solicita una atención muy precisa a los términos mismos que lo componen. ${ }^{4}$

Será Lacan quien sistematizará toda la problemática a través de la autonomía del significante, un significante que, como profundizaremos más detenidamente en la segunda parte del artículo, es sin sentido y sin articulación, un significante no comprendido, en definitiva, una huella que conmemora la repetición de un goce perdido.

Para entender, al menos previamente, la mentada "autonomía del significante", recurriremos a unos de los casos clínicos del padre del psicoanálisis:

[...] el Hombre de las Ratas, en Freud, se ve preso bruscamente de la impulsión de adelgazar. Pero esta impulsión permanece incomprensible hasta tanto no se haya revelado

\footnotetext{
3 Fue precisamente la paciente Anna O. quien determinó el tratamiento bajo el lema "talking cure". Es importante subrayar que la toma de conciencia no precede la verbalización de la cual ésta sería la expresión realizada. El síntoma, de hecho, ocupa el lugar de la verbalización que nunca fue presente (en el momento del trauma), y que desaparece -el síntoma-, cuando por fin se verbaliza el afecto reprimido a través del significante perdido. Se trata de una significación con valor retroactivo. Es sabido que a partir de 1892 para Freud, gracias en parte a los estudios realizados con el neurólogo francés Jean-Martin Charcot en los años 1885-1886, el síntoma de conversión histérico, lejos de ser una simulación, es la expresión de lo reprimido. Recordaremos, de paso, como el psicoanálisis nace del estudio de la histeria, una neurosis marcada por el polimorfismo de sus manifestaciones. Es, de hecho, desde esta estructura clínica -a la que se añaden la psicosis y la perversión- que se funda el movimiento psicoanalítico.

${ }^{4}$ Chemana R.; Vandermersch B., Diccionario del Psicoanálisis, Buenos Aires - Madrid, Amorrortu editores, 2004, p. 623.
} 
que en la lengua que habla, el alemán, gordo se dice "dick”, y que Dick es también el nombre de un rival del que quisiera deshacerse. Adelgazar es matar a Dick, el rival. En el límite, la posibilidad misma del inconsciente está condicionada por el hecho de que un significante puede insistir en el discurso de un sujeto sin ser asociado por ello a la significación que podría importar para él. "El lenguaje es la condición del inconsciente"5

De esta manera, concibiendo el significante autónomo respecto a la significación, tomará otra función que no será la de significar, sino la de representar y determinar el sujeto. Nos hallamos frente al núcleo fundamental del escrito citado más arriba: "La instancia de la letra en el inconsciente, o la razón después de Freud", en el cual Lacan identifica la letra "como la estructura esencialmente localizada del significante"6. En ella la significación queda incumplida aún cuando, pudiendo afirmar que en la cadena del significante el sentido sigue insistiendo, es patente, a la luz de la experiencia analítica, que ninguno de los elementos de la cadena consiste en la significación7. Volvemos otra vez al tema, poco antes señalado, del significante incomprendido, pero que funciona como un imperativo al goce8; un significante, en definitiva, al cual se obedece ciegamente a través de la repetición. En esto consiste la cadena significante ${ }^{9}$

Un significante, una marca, una huella. En definitiva es el inconsciente que se presenta, a través de sus representantes, como el capítulo de mi historia que está censurado. La verdad, como nos recuerda Lacan, se puede reencontrar:

\footnotetext{
${ }^{5}$ Chemana; Vandermersch 2004, op. cit. (nota 4), p. 624. Aclaramos que lo que se reprime en la cadena de significantes es un significado "traumático", algo molesto que se tiene que excluir de la consciencia, es decir, se reprime por algo, no es aleatorio. Lo traumático es algo que no se puede tramitar a nivel de la conciencia y por ello se reprime. Además, el trauma no tiene por qué ser una escena terrible, sino algo que sorprende porque no se le pueden encontrar, en ese momento, recursos simbólicos. 6 Lacan 2008, op. cit. (nota 1), p. 469.

7 Ibídem, p. 470.

${ }^{8}$ La relación entre el significante y el goce será tratada en el segundo capítulo: Lacan I, Lacan II.

9 Tomemos un ejemplo simple. Un homosexual confiesa de buen grado su gusto por los jóvenes de cierto estilo y de cierta edad, aquellos que designa perfectamente para él la expresión "los soldaditos". El análisis traerá un recuerdo de un entendimiento muy grande con su madre, recuerdo cristalizado alrededor de la evocación de aquellas tardes de verano en las que, luego de un largo paseo, ella lo llevaba al café y pedía: “Ah, para él, una sodita [más homofónico en francés con soldadito]”. Tal recuerdo no implica, evidentemente, que, según el psicoanálisis, todo se aclara en una vida con la evocación de algunas palabras oídas en la infancia. Pero contribuye a caracterizar la función del significante para el sujeto humano. La manera en que este hombre nombra al objeto de su deseo, y así determina sus rasgos, lo remite a un significante oído en la infancia, que insiste tanto más cuanto no ha sido reconocido como tal. Según la fórmula de Lacan, "un significante es lo que representa al sujeto para otro significante". Hay que destacar también aquí que lo que cuenta en "soldado" no es su significación, en relación por ejemplo con la vida militar, sino su significancia, o sea, lo que es producido directamente por la imagen acústica de la palabra misma. Chemana; Vandermersch 2004, op. cit. (nota 4), p. 625.
} 
- En los monumentos: y esto es mi cuerpo, es decir, el núcleo histérico de la neurosis donde el síntoma histérico muestra la estructura de un lenguaje y se descifra como una inscripción que, una vez recogida, puede sin pérdida grave ser destruida.

- En los documentos de archivo también: y son los recuerdos de mi infancia, impenetrables tanto como ellos, cuando no conozco su proveniencia.

- En la evolución semántica: y esto responde al stock y a las acepciones del vocabulario que me es particular, como al estilo de mi vida y a mi carácter.

- En la tradición también, y aún en las leyendas que bajo una forma heroificada vehiculan mi historia.

- En los rastros, finalmente, que conservan inevitablemente sus distorsiones, necesitadas para la conexión del capítulo adulterado con los capítulos que lo enmarcan, y cuyo sentido restablecerá mi exégesis. ${ }^{10}$

El significante enigmático, misterioso, incomprendido, representa al sujeto por otro significante, constituyendo la que se denomina "cadena significante", una cadena de huellas que determina el sujeto en su destino más allá de sus actos. En la identificación simbólica el sujeto se representa por un significante, lo que Lacan desarrollará como S1, signifiant-maître, significante amo. No adelantaremos acontecimientos ya que del significante amo trataremos en la segunda parte del artículo, pero sí haremos hincapié en un aspecto central del psicoanálisis: el lenguaje es la condición misma del inconsciente. Los lapsus, una de las vías privilegiadas al inconsciente, demuestran cómo la polisemia de los significantes traduce (del latín traducere, hacer pasar más allá) no sólo un doble sentido de las palabras, sino la verdad (del deseo) frente a la exactitud o certeza de la afirmación, la cual, muchas veces, está bien lejos de traducir la realidad del ser hablante11

La atención a la palabra, a la asociación libre, durante la cual el paciente expresa todo lo que se le ocurre sin discriminación, formará lo que se puede denominar como una teoría psicoanalítica del lenguaje y que tiene su punto de surgimiento durante el tratamiento de pacientes histéricas, en las cuales Freud se da cuenta de que el síntoma patente no es el núcleo de la enfermedad - por lo cual no basta tratar el síntoma como tal-, sino que reenvía a un conflicto latente. Como anticipado en la nota tercera, el tratamiento del síntoma emprendido por Freud es radicalmente

\footnotetext{
10 Lacan 2008, op. cit. (nota 1), pp. 251-252.

11 El ejemplo que aquí proponemos ayudará a esclarecer lo anteriormente comentado: "Cuando un caballero que conversa con una dama (Freud, Psicopatología de la vida cotidiana) le pregunta: " ¿Vio usted la exposición de la casa Wertheim? Está muy bien descotada", sabemos que debe oírse aquí un lapsus. No se trata forzosamente de que el deseo del caballero sea particularmente inconsciente: él ha admitido desde el comienzo el escote de la dama. Pero este ejemplo es interesante para Freud por otra razón. "Huelga decir -añade- que la palabra exposición adquiere con este lapsus un doble sentido". En suma, lo que antes del lapsus permitía al deseo decirse sin que el propio caballero se percatara, lo que el lapsus permite simplemente señalar como tal, es el doble sentido de la palabra exposición." Chemana; Vandermersch 2004, op. cit. (nota 4), pp. 392-393.
} 
distinto al de sus contemporáneos: lejos de reenviar a sí mismo y, en consecuencia, abordar el síntoma como tal, Freud capta en él su carácter de remisión. Esta característica de remisión del síntoma que se extenderá paulatinamente a los otros elementos claves del análisis, es la base sobre la cual el padre del psicoanálisis podrá edificar su construcción ${ }^{12}$

El lenguaje como condición del inconsciente, o, según la famosa fórmula lacaniana según la cual "el inconsciente está estructurado como un lenguaje", encuentra su punto álgido en el momento en que los dos mecanismos primarios a través de los cuales el inconsciente "habla", son retraducidos en las figuras retóricas de la metáfora y la metonimia, que manifiestan los mecanismos primarios inconscientes en el habla13. El valor del significante nunca es unívoco y no solamente se distingue de los otros significantes en virtud de que en la lengua no hay más que diferencias $^{14}$, sino que se distingue de sí mismo ${ }^{15}$

Queda patente que en la práctica analítica se le asigna una dimensión significante a lo que se oye $-\mathrm{y}$ esto afecta no solamente los lapsus, sino las repeticiones, los enunciados, etc.- ya que el inconsciente habla a través de una estructura que, reducida a los mínimos términos, es la misma del lenguaje: repetición y diferencia ${ }^{16}$.

12 Por límites de espacio y tiempo no nos podemos permitir explayarnos mucho, pero recordaremos lo siguiente: "Es sin embargo con motivo del análisis de los lapsus, de los actos fallidos y sobre todo de los sueños, de las formaciones del inconsciente, en suma, cuando Freud avanzará más en lo que constituye una suerte de puesta en acción de una teoría psicoanalítica del lenguaje. Observemos al respecto que no es seguro que esta teoría en sí pueda ser sistematizada, pero el lector atento habrá de advertir de qué modo trabaja en los análisis concretos de Freud o de Lacan. El sueño constituye un campo privilegiado. Fue con relación al sueño como Freud describió primeramente los mecanismos de condensación y desplazamiento, que Lacan iba a vincular a la metonimia y a la metáfora". Chemana; Vandermersch 2004, op. cit. (nota 4), pp. 393-394.

$13 \mathrm{La}$ importancia otorgada a las figuras retóricas de la metonimia y de la metáfora, acompañan a Lacan durante toda su obra. Para esclarecer aún más la motivación de la elección propondremos la siguiente cita del seminario XVIII: "La última vez articulé que, si se consideran las cosas en el punto en que efectivamente pueden interrogarse, ese que atañe al discurso más común, si queremos, no empujar a su término lo que la lingüística nos indica, sino justamente extrapolarlo, percibimos que nunca nada de lo que el lenguaje nos permite hacer es más que metáfora o bien metonimia. Lo que toda palabra, sea cual fuere, pretende por un momento nombrar no puede nunca más que remitir a una connotación". En Lacan J., El Seminario, Libro XVIII, De un discurso que no fuera del semblante, Buenos Aires, Paidós, 2009, p. 157.

14 Saussure F., Curso de lingüística general, Buenos Aires, Editorial Losada, 2002, pp. 211-218.

15 Si yo digo: "mi abuelo es mi abuelo", "abuelo" adquiere en cada una de estas dos ocurrencias un valor específico. Por ejemplo, el primero puede remitir a un individuo del que acabo de hablar pestes, mientras que el segundo estará ahí para reconocer que ese infame individuo sigue siendo el padre de mi padre. En Chemana; Vandermersch 2004, op. cit. (nota 4), pp. 395-396.

${ }^{16}$ La temática de la "repetición" es demasiado amplia para que sea siquiera esbozada en este trabajo. Aún así apuntaremos que la repetición (Wiederholung) remite directamente al trauma que no está simbolizado y que por ello vuelve a presentarse - una y otra vez sin cesar- en las conductas, en los discursos o en las situaciones del sujeto sin que este lo sepa. El mecanismo de la repetición, que evolucio- 
Para ultimar esta introducción, haremos referencia a los tres registros: real, simbólico, imaginario, sin los cuales la obra entera de Lacan resultaría de difícil interpretación. Este conjunto acompañará a Lacan durante toda su obra y será el objeto de uno de sus seminarios más tardíos, titulado R.S.I, del año 1974-197517. Este conjunto se dio a conocer en una conferencia de 1953, Lo simbólico, lo imaginario y lo real ${ }^{18}$, y continuará en el primer seminario en el capítulo séptimo: La tópica de lo imaginario ${ }^{19}$. Anticiparemos que no es posible tratar de un registro sin tener en cuenta los restantes. Aún así, lo imaginario -como la palabra sugiere- se relaciona con la imagen y más exactamente con la identificación como señuelo/impostura (del francés leurre). Habrá que recordar, para esclarecer lo que Lacan entiende por "imaginario", el famoso "estadio del espejo" 20 , una de las teorías de Lacan más antiguas. Esta fase o estadio se sitúa en los primeros meses de vida del ser humano, más precisamente entre los seis y los dieciocho. En este momento el infante se caracteriza por la inmadurez del sistema nervioso y se vive como despedazado, en el sentido de que no hace ninguna diferencia entre él y el cuerpo de la madre. Lo cual significa que, en este momento, tampoco hay diferencia entre él y el mundo exterior. El yo, en Lacan, no es el dato originario de la vida psíquica del individuo, sino el resultado de una construcción. Es lo que sucede cuando el niño reconoce la propia imagen en el espejo y se elabora un primer bosquejo del yo, pero a través de lo imaginario, lo cual significa en una relación dual en la cual se instaura una confusión entre sí y el otro. Esta identificación se presenta como primaria, matriz de todas las demás, por ejemplo con la madre. ${ }^{21}$

nará en la coerción de repetición (Wiederholungszwang), está dominado por el principio de placer. Según Lacan este concepto, con los de inconsciente, pulsión y transferencia, constituyen los cuatro conceptos fundamentales del psicoanálisis que serán tratados en el seminario del año 1964 (Lacan., El Seminario, Libro XI, Los Cuatro Conceptos Fundamentales del Psicoanálisis, Buenos Aires, Paidós, 1987).

17 Inédito.

18 Lacan J., De los nombres del Padre, Buenos Aires, Paidós, 2005.

19 Lacan J., El Seminario, Libro I, Los Escritos Técnicos de Freud, Buenos Aires, Paidós, 2004, p. 119166.

20 Lacan 2008, op. cit. (nota 1), pp. 99-105.

${ }^{21}$ Llevado por su madre [el niño], va a reconocer su imagen en el espejo, anticipando imaginariamente la forma total de su cuerpo. Pero el niño se vive y se posiciona en primer lugar como otro, el otro del espejo en su estructura invertida; así se instaura el desconocimiento de todo ser humano en cuanto a la verdad de su ser y su profunda alienación en la imagen que va a dar de sí mismo. Chemana; Vandermersch 2004, op. cit. (nota 4), p. 345. Es importante subrayar que es en esta identificación se puede percibir la "impostura" a la que se refiere Lacan: "Basta para ello entender el estadio de espejo como una identificación en el sentido pleno que el análisis da a este término: a saber, la trasformación producida en el sujeto cuando asume una imagen, cuya predestinación a este efecto de fase está suficientemente indicada por el uso, en la teoría, del término antiguo imago. El hecho de que su imagen especular sea asumida jubilosamente por el ser sumido todavía en la impotencia motriz y la dependencia de la lactancia que es el hombrecito en ese estadio infans, nos parecerá por lo tanto que manifies- 
A lo "simbólico" pertenece el lenguaje, la experiencia de la palabra, la esencia del intercambio, lo que hace del hombre un ser regido - en el sentido más amplio de la palabra- por el lenguaje. Esto determina el ser hablante en sus lazos sociales y en su aspecto sintomático, gobernado por la disposición del juego de los significantes. ${ }^{22}$

Por un lado encontramos la función imaginaria del yo en cuanto unidad del sujeto alienado de sí mismo. El yo es entonces aquello en lo cual el sujeto se reconoce, como hemos visto, a un alto precio: alienándose. Por el otro lado lo "simbólico", aquello en lo cual el sujeto se empeña en una relación propiamente humana y que reúne también: tumbas, grabados murales, túmulos, signos marcados en la piedra, en definitiva: la civilización.

Habrá que hacer un importante inciso: el padre en cuestión no tiene nada de real, que se pueda atestiguar en lo biológico, sino que encarna la función paterna reconducida por Lacan al "Nombre del Padre" 23 y que, interviniendo para reprimir el deseo del hijo a quedar subyugado al deseo de la madre, promueve el acceso al orden simbólico del lenguaje. Es por ello que en el nombre del padre hay que reconocer el fundamento de la función simbólica que, desde los inicios, identifica su persona con la figura de la ley. Sin podernos prolongar mucho más, añadiremos que la entrada en el orden simbólico determina una separación entre el yo consciente y el Inconsciente, el cual se define sobre la base de la interiorización de la trama de los significantes propios de una determinada sociedad o cultura. La génesis del inconsciente es así la otra cara del medallón de la constitución del "yo". El yo para poderse definir necesitará de la palabra, de ese instrumento que le consiente y posibilita expresar significantes. El Inconsciente es de esta forma el tejido y la trama de los significantes, el sistema de la lengua que permite hablar. Entonces el pasaje del animal al hombre adviene a través de la conformidad a un orden simbólico que llega como una ley, un legado. Este legado en cuanto trama o encadenamiento de significantes, estructura el Inconsciente mientras asigna al yo una identidad ilusoria, imaginaria y mistificadora. El advenimiento del hombre coincide por tanto con una escisión (Spaltung) entre el psiquismo inconsciente y la conciencia subjetiva. La consecuencia de esta división es que el inconsciente se estructura como un lengua-

ta, en una situación ejemplar, la matriz simbólica en la que el yo [je] se precipita en una forma primordial antes de objetivarse en la dialéctica de la identificación con el otro y antes de que el lenguaje le restituya en lo universal su función de sujeto". Lacan 2008, op. cit. (nota 1), p. 100.

${ }^{22}$ La temática ya citada de la identificación primaria con la madre nos ayudará también a caracterizar mejor el registro simbólico: es respecto a la relación especular de los deseos de la madre y del niño como intercede la figura paterna $-\mathrm{y}$ con ella la interdicción del incesto, la primera ley que originaría, según Freud, la civilización-, en los cuales se instituyen el orden simbólico y la ley como fundamento de la civilización. El padre es la figura de la ley y es, propiamente, una figura simbólica. Es a través de este orden, o sea con el lenguaje, como se accede a la sociedad y a la cultura, con todo el malestar que puede derivarse

23 Para aquellos que quieran profundizar la temática de "le Nom du Pére", reenviamos al título: Lacan J., De los nombres del Padre, Buenos Aires, Paidós, 2005. 
je, lo cual significa que está completamente subordinado al orden simbólico, mientras el yo queda prendido en la captación de la imago, o lo que es lo mismo, del narcisismo imaginario.

Antes de abordar el último registro, lo "real", no hay que olvidar que los tres registros se entrecruzan constantemente, están ligados entre sí. Para ello Lacan recurrirá a la imagen del nudo borromeo, un enlace en el cual si se separa uno de los aros, se liberan los restantes. A partir del Seminario XXIII del año 1975-1976, Le sinthome ${ }^{24}$, Lacan añadirá que lo que liga los tres registros entre sí es precisamente el sinthome, el síntoma, que no sería otra cosa que el "padre".

Volviendo a los tres registros, lo "real" es siempre algo que choca con una cierta violencia: es, por ejemplo, el silencio del analista en una sesión. El definir lo real como lo imposible es siempre lo que no se puede simbolizar completamente en la palabra y, por consiguiente, no cesa de no escribirse. Lo siniestro (Unheimlichkeit Gefühl) es otro buen ejemplo de lo que Lacan define como lo "real": lo familiar que se vuelve siniestro 25 . Es fácil captar cómo no se puede hablar de lo "real" sin prever una dimensión imaginaria -en la cual siempre estamos sumidos-atravesada por lo simbólico.

Durante la continuación del artículo volveremos una y otra vez sobre los tres registros lacanianos. Por limitaciones de tiempo y espacio no podremos explayarnos acerca de otros conceptos fundamentales para el psicoanálisis en general y para Lacan en particular cuales el Falo, el esquema L, el fantasma, etc. 26

En otro lugar habría que tratar como se merece el encuentro/desencuentro entre Lacan y Derrida acerca de lo publicado por éste en su "Le facteur de la verité"27, texto de 1975 que comenta el "Seminario sobre La carta robada", que, recordémoslo de paso, es de 1956. Será importante subrayar, y lo haremos en la tercera parte del artículo, las numerosas metáforas que también utiliza Lacan acerca de la escritura y la huella, metáforas que tienen mucho en común con las que Derrida dilucidó en su conferencia pronunciada en el Institut de psychanalyse en marzo de 1966,

\footnotetext{
24 Lacan J., El Seminario, Libro XXIII, El sinthome, Buenos Aires, Paidós, 2006.

25 Precisaremos que lo "siniestro" será extendido después de Freud -que lo relacionaba principalmente con un sentimiento de extrañeza y malestar frente a un objeto animado o inanimado antes familiar- a aquello que, apareciendo en lo real, recuerda directamente y de forma demasiado brusca, lo más intimo. 26 Del "objeto $a$ " como causa del deseo y el Otro (Autre) trataremos en la segunda parte del artículo: "Lacan I, Lacan II". Acerca del Falo añadiremos brevemente que es por un lado el símbolo de la libido para los dos sexos $-\mathrm{y}$, dicho sea de paso, una de las fases por las que pasa el sujeto, en este caso entre los tres y los seis años-, por otro el significante que designa el conjunto de los efectos del significante sobre el sujeto y, adentrándonos en lo particular, la pérdida ligada a la captura de la sexualidad en el lenguaje. Recordaremos que el Falo en Lacan no tiene ninguna relación con el órgano anatómico: se trata, como hemos dicho, de un significante -y ahora añadiremos "metafórico"-, que hace referencia a la falta a ser constitutiva de toda subjetividad. En este sentido, la imagen en la comentada "fase del espejo", es fálica.

27 Derrida J., El concepto de verdad en Lacan, Buenos Aires, Homo Sapiens, 1977.
} 
"Freud et la scène de l'écriture"28, acerca de un artículo de Freud titulado "Nota sobre la Pizarra mágica" (Wunderblock)29, donde éste compara la pizarra de celuloide, que acaba de ser comercializada, denominada "pizarra mágica", con el aparato psíquico. El aspecto significativo, entre otros, que subraya Derrida, es que sobre esta pizarra la escritura puede ser borrada pero la huella de la escritura queda impresa ${ }^{30}$. Quizás ya esta sea una deconstrucción de Lacan más efectiva que la contenida en "Le facteur de la verité", pero dejaremos de lado esta cuestión. Añadiremos que la objeción central de Derrida es que la letra/carta ${ }^{31}$ sería en el escrito de Lacan "intangible e indestructible".

Lo que hemos tratado de hacer en esta introducción es resumir -con todo lo que tiene de limitado e injusto esta práctica, y más tratándose de uno de los pensadores que han influido mayormente en el siglo XX-, los comienzos y las líneas directrices de la doctrina lacaniana, líneas que se modificarán significativamente en los años venideros y que tomarán un giro inesperado y concreto en el Seminario del año 1969-1970: "El Reverso del Psicoanálisis"32.

\section{Lacan I, Lacan II}

El final de los años sesenta y el comienzo de los setenta señala un cambio importante en la doctrina de Lacan. Los cambios sociales no dejan indiferente al psicoanalista francés, cambios sociales que marcarán una época: el aterrizaje en la luna, las revueltas estudiantiles, la des-colonización, la guerra de Argelia, la máquina del capitalismo.

Todo esto se manifiesta en un seminario, el XVII, El Reverso del Psicoanálisis, empezado a finales de los sesenta y concluido en junio del año siguiente. Aquí Lacan pone al desnudo el psicoanálisis, a Freud y hasta a sí mismo. La figura del psicoanalista como maestro de la verdad -que se podía palpar en los Escritos y en los seminarios de los años cincuenta y sesenta-, de una verdad (o función de la verdad) que sería descuidada por los filisteos del saber, ahora, esta verdad, será "devaluada". Aquí, en este seminario, ya no hay lugar para la "palabra inspirada", ésta -la palabra- está rigurosamente constreñida por una estructura que la precede y que son los tipos de enunciación que Lacan llama "Discursos", los cuales se determinan a

\footnotetext{
28 Derrida J., La escritura y la diferencia, Barcelona, Editorial Anthropos, 1989, pp. 271-317.

29 Freud S., Obras completas vol. XIX, Buenos Aires, Amorrortu editores, 1979, pp. 239-247.

30 Un mecanismo que nos recuerda el "palimpsesto" (del lat. palimpsestus, y este del gr. $\pi \alpha \lambda i \mu \psi \eta \sigma \tau \varsigma \varsigma)$, una tablilla antigua en la que se podía borrar lo escrito para volver a escribir, y que conservaba las huellas de una escritura anterior borrada artificialmente.

31 En francés lettre indica la "carta" como la "letra".

32 Lacan J., El Seminario, Libro XVII, El Reverso del Psicoanálisis, Buenos Aires, Paidós, 1997.
} 
partir de la posición del sujeto relativa a un cierto número de funciones: el lugar del agente o semblante, el lugar del Otro (Autre), el lugar de la producción y el lugar de la verdad:

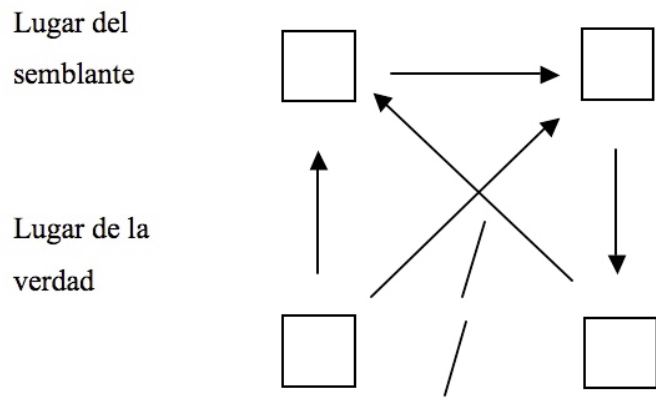

Lugar del

Otro (Autre)

Lugar de la

producción

La estructura que presentamos es lo que Lacan define un "discurso sin palabras": "Resulta que el año pasado distinguí, de forma muy insistente, el discurso como una estructura necesaria que excede con mucho a la palabra, siempre más o menos ocasional. Prefiero, dije, incluso lo escribí un día, un discurso sin palabras"33. Lacan reduce a cuatro los discursos que se presentan a través de unos mathemas:

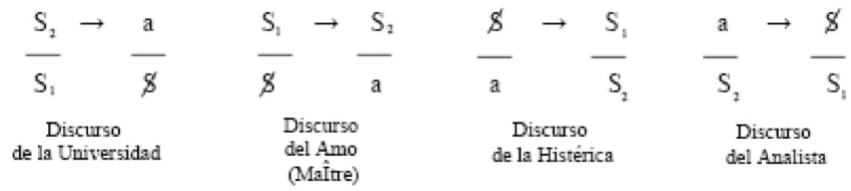

Cada mathema es un discurso con cuatro términos que se disponen en un orden fijo: S1, el significante amo (signifiant-maître), S2, el saber, $\$$, el sujeto y $a$, el plus de goce (plus-de-juir). La rotación de un cuarto de giro de la serie $\mathrm{S} 1, \mathrm{~S} 2, \$, a$, produce una estructura discursiva específica ${ }^{34}$ que son los cuatro discursos. Cada lugar tiene una función específica:

El "lugar del semblante (o agente)" es la posición que domina el discurso y más propiamente aquello que hace funcionar el discurso. El semblante se puede definir como el efecto de una verdad que le es desconocida y por ello el lugar del semblante es también el de la apariencia ${ }^{35}$.

\footnotetext{
33 Lacan 1997, op. cit. (nota 32), p. 10.

34 Para quien quiera profundizar la temática de los discursos lacanianos reenviamos a los siguientes textos: Lacan 1997, op. cit. (nota 32); Lacan J., Radiofonía y Televisión, Barcelona, Editorial Anagrama, 1977; Alemán J.; Larriera S., Desde Lacan: Heidegger. Textos reunidos, Málaga, Miguel Gómez Ediciones, 2009.

35 Cimmarelli S, "Una lettura introduttiva ai quattro discorsi di Lacan", Attualitá lacaniana, (11) 2010, p. 154.
} 
El "lugar del Otro (Autre)" en tanto que lugar de la alteridad, es el lugar al cual el discurso se refiere 36 .

El "lugar de la producción" es a la vez el lugar de una cierta pérdida en lo que produce el discurso 37

El "lugar de la verdad" está debajo de la barra de la represión y es el lugar que funda el discurso ${ }^{38}$, situado debajo del lugar del agente. El vector que se dirige hacia el semblante, indica cómo es la verdad (desconocida) que funda la apariencia del discurso. También es digno de atención cómo no hay paso entre el lugar de la verdad y el de la producción, en cuanto la primera no se determina a partir de otro. Al revés, es el lugar de la verdad que decreta -en cuanto se dirige- los dos lugares del discurso manifiesto: el del semblante y del Otro.

Como anunciado más arriba, los cuatro términos $\mathrm{S} 1, \mathrm{~S} 2, \$, a$ siguen un orden de sucesión inalterable. Obviamente, más allá de lo que cada término pueda indicar por sí sólo, su propiedad se modificará según el lugar que ocupe. Antes de retraducir el discurso que fundamenta los restantes, el discurso del amo (maître), analizaremos brevemente lo que cada uno de estos términos indica:

S1, el significante amo, el significante que representa el sujeto por otro significante (S2). Lo que Lacan afirma acerca de este significante enigmático, un significante que es una marca no articulada -sino un rasgo unario-, es lo que nos permitirá centrarnos sobre que aquello que produce un cambio en la doctrina lacaniana, el paso del Lacan I al Lacan II.

$\mathrm{S} 2$ es el saber o, más propiamente, aquel significante por el cual S1, la marca enigmática, recibe una aclaración a partir de este segundo significante (S2). Es a partir de esta mínima cadena significante S1-S2 que la marca deviene significante en un funcionamiento de après coup (posterioridad) del significante mismo, en el sentido que el primero (el significante amo) en su delinearse en cuanto enigmático, recibe sólo a partir del segundo una aclaración produciendo de este modo un efecto de significación.

Si el primer Lacan puso de manifiesto la evidencia del efecto de sentido y de verdad de la cadena significante en cuanto sometimiento a la misma, el segundo Lacan -que se anuncia en el Seminario XVII- añade que al efecto de verdad y sentido se suma el efecto de goce (jouissance). El efecto de goce, o como Lacan, para producir un malentendido ambiguo, escribe "jouis-sens" (gozar-sentido o gozar de sentido) es lo que indica con la pequeña $a$. Es el objeto como falta y como causa del deseo.

En todo esto hemos dejado abierta la cuestión del sujeto, un sujeto que es el resultado de la relación entre $\mathrm{S} 1$-el significante que representa el sujeto- y $\mathrm{S} 2$, el

\footnotetext{
36 Cimmarelli 2010, op. cit. (nota 35), p. 154

37 Ibidem, p. 154.

38 Ibidem, p. 155.
} 
otro significante. Es un sujeto dividido que deja de ser significante para ser significado y que nos define el sujeto del psicoanálisis: el sujeto que se modificaría a partir del significante, o mejor dicho, inscribiéndolo como efecto de significación. El sujeto es, en Lacan, un efecto de significación (de la cadena S1-S2) y la fórmula S barrada $(\$)$ es el significante del sujeto. Todo ello se refleja en la matriz de todos los discursos, el del amo que aquí presentamos:

$$
\frac{\mathrm{S}_{1}}{\mathrm{~s}} \rightarrow \frac{\mathrm{S}_{2}}{\mathrm{a}}
$$

En este discurso la mínima cadena significante S1-S2 es el punto de emergencia del sujeto $\$ .39$

La puesta en función del discurso matriz se define por una distinción fundamental entre el significante amo y el saber. El resultado es que el (significante) sujeto $\$$ se encuentra vinculado con el significante amo mientras que el goce como producción se debe al saber. Pero entre la pequeña $a$ y el sujeto del significante no hay posibilidad de encuentro: el goce, en este sentido, se traduce como resto.

Para apreciar mejor el significado que asume cada término según el lugar que ocupe, analizaremos otro discurso, el de la histérica ${ }^{40}$ :

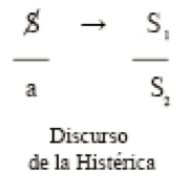

Se puede apreciar en la disposición de los términos unas diferencias importantes con respecto al "discurso del amo". El lugar del semblante está ocupado por el sujeto barrado que encarna el síntoma como división en el sujeto (inhibición, síntoma, angustia) 41 . En el "lugar del Otro" el significante amo S1 no inaugura la cadena significante que producirá el goce, sino que representa ese saber reprimido que

\footnotetext{
${ }^{39}$ Hay estructuras - no podemos designarlas de otro modo- para caracterizar lo que se puede obtener de ese en forma de que el año pasado me permití acentuar con un uso específico, es decir, lo que se produce por la relación fundamental, tal como la defino, de un significante con otro significante. De ello resulta la emergencia de lo que llamo el sujeto -por el significante que, en cada caso, funciona como representando a este sujeto ante otro significante. En Lacan 1997, op. cit. (nota 32), p. 10.

$40 \mathrm{El}$ término francés hystérique indica tanto el género masculino como el género femenino. En el Seminario XVII el texto apunta claramente hacia la figura de la histérica por lo que se ha optado, como en el mismo Seminario, por traducirlo con el adjetivo al femenino "histérica".

41 Es útil recordar que en el cuadro freudiano la histeria es una neurosis que se define como una "defensa contra la castración por fijación a un escenario edípico"; en Chemana; Vandermersch 2004, op. cit. (nota 4), p. 441. Añadimos que para Lacan, en la histeria, la cuestión de la identidad sexual es central: las preguntas son: ¿soy hombre o mujer? y ¿qué es una mujer?
} 
el discurso de la histérica interroga para producir un saber S2 que se configura como pérdida. La verdad en cuanto goce $(a)$ que funda el sujeto del significante en el discurso de la histérica es enteramente extraña al sujeto. Este discurso es importante porque es el modelo del discurso con el que el analizando se presenta, un discurso típicamente neurótico. Su semblante de sujeto dividido movido por un saber sexual reprimido, interroga desde sus significantes en souffrance ${ }^{42}$ el otro como sujetosupuesto-saber (aunque, de hecho, no lo sea) produce un saber que deja un resto irreducible en el lugar de la verdad, ese goce que repite una y otra vez las preguntas del sujeto43.

Para concluir la segunda parte, proponemos una larga cita que ayudará a distinguir lo que Lacan entiende por "sujeto del significante":

Y ahora viene lo que aporta Lacan. Se refiere a esta repetición, esta identificación del goce. En este punto, tomo algo prestado del texto de Freud, dándole un sentido que éste no indica, la función del rasgo unario, es decir, la forma más simple de la marca, que es el origen del significante propiamente dicho ${ }^{44}$. Y aquí les adelanto -cosa que no se ve en el texto de Freud, pero que el psicoanalista no puede dejar de lado, evitar o rechazar- que todo lo que a nosotros, analistas, nos interesa como saber se origina en el rasgo unario.

En efecto el psicoanálisis se origina en el vuelco por el cual el saber se purifica (s'épure), si puedo decirlo así, de todo lo que pueda confundirlo con un saber natural tomándolo por un no sé qué que supuestamente nos guiaría en el mundo circundante, con la ayuda de no sé qué papilas que habría en nosotros y que sabrían orientarse de forma innata. No es que no haya nada parecido. Cuando un sabio psicólogo escribe en nuestros días [...] algo llamado La sensación, guía de la vida ${ }^{45}$, no está diciendo nada absurdo, por supuesto. Pero si puedo anunciarlo así, es precisamente porque toda la evolución de una ciencia nos hace ver que no hay ninguna connaturalidad de esta sensación con respecto de la aprehensión de un pretendido mundo que pueda surgir por medio de ella. Si la elaboración propiamente científica, la indagación de los sentidos de la vista, del oído incluso, nos demuestra algo, no es más algo que debemos recibir tal y como es, exactamente con el mismo coeficiente de facticidad con el que se presenta. Entre las vibraciones luminosas hay un ultravioleta del que no tenemos ninguna percepción [...] Otro tanto ocurre con el oído [...]

En realidad, si lo vemos de esta manera, lo único que puede captarse es que hay filtros y que nos las arreglamos con estos filtros. La función, dicen, crea el órgano. Por el contrario, nos servimos del órgano como podemos. Eso sobre lo que ha querido razonar, en

\footnotetext{
42 Este término denota tanto el sufrimiento como la espera.

43 La interrogación en el "lugar del Otro" como significante amo, remite a otra fórmula lacaniana: "el deseo es el deseo del Otro" en tanto que el deseo del hombre encuentra su sentido en el deseo del otro, no porque éste detenga las llaves del objeto deseado, sino porque el primer objeto es de ser reconocido por el otro. En Lacan 2008, op. cit. (nota 1), p.259.

44 Subrayado nuestro. Lo aclararemos en la página 32.

45 Piéron H., La sensation, guide de vie, París, Gallimard, 1950.
} 
relación con los mecanismos del pensamiento, toda una filosofía tradicional que trabajó en la dirección que ustedes conocen, mediante la descripción de lo que se produce en el nivel de la abstracción, de la generalización, edificando esto sobre una especie de reducción, de filtrado, de una sensación que se considera basal-Nihil fuerit in intellectu quid, etc.-, este sujeto, este sujeto deductible como sujeto del conocimiento, este sujeto que se puede construir de una forma que ahora nos parece tan artificial, a través de aparatos u órganos vitales de los que, en efecto, no se puede prescindir, ¿se trata de esto en la articulación significante? articulación en la que pueden empezar a intervenir esos primeros términos que se deletrean, esos que desplegamos aquí, esos términos, los más elementales, que anudan, como ya he dicho, un significante con otro significante, y que tienen efectos, por el hecho de que en su definición este significante sólo es manejable si eso tiene sentido, que representa a un sujeto, un sujeto y ninguna otra cosa, para otro significante.

No, no hay nada en común entre el sujeto del conocimiento y el sujeto del significante. No hay forma de evitar esta fórmula extraordinariamente reducida que dice que debajo hay algo. Pero precisamente no podemos designar este algo con ningún término. No

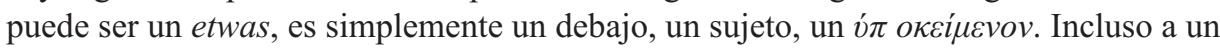
pensamiento tan aplicado a la contemplación de las exigencias, primarias y no construidas, de la idea de conocimiento, me refiero al pensamiento de Aristóteles, el sólo acceso a la lógica, el hecho de introducirla en el circuito del saber, le impone distinguir seve-

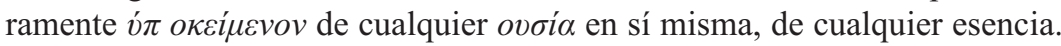

Así, el significante se articula representando a un sujeto ante otro significante. De aquí es de donde partimos para dar sentido a esa repetición inaugural en tanto repetición que apunta al goce.

El saber, a cierto nivel, está dominado, articulado por necesidades puramente formales, necesidades de la escritura, lo que en nuestros días conduce a cierto tipo de lógica. Ahora bien, este saber al que podemos conceder el apoyo de una experiencia que es la lógica moderna, ante todo manejo de la escritura, este tipo de saber es el mismo que está en juego cuando se trata de medir la incidencia de la repetición en la clínica analítica. En otros términos, el saber que más depurado (épuré) nos parece, aunque está bien claro que no podemos obtenerlo de ninguna forma por depuración (épuration) a partir del empirismo, es ese mismo saber el que se encuentra introducido desde el origen 46

\section{La función de la escritura}

La larga cita con la que hemos concluido la segunda parte del artículo, nos servirá para introducirnos en el tema de la función de la escritura. No es que hasta ahora no se haya hecho, pero la atención se ha centrado más en el significante y su condición de marca.

Lacan, a lo largo de su extensa trayectoria, trata en contadas ocasiones el tema de la escritura y siempre para subrayar su ser producto, derivación del lenguaje. En

46 Lacan 1997, op. cit. (nota 32), pp. 47-51. 
el Seminario IX, "La identificación" (1961-62)47, se encuentra una teoría de la génesis de la escritura, de cómo fue fonetizada en el momento en que las marcas sobre las cerámicas egipcias se volvieron signos de escritura. Sin embargo no es en éste seminario y de lo tratado en él donde se centrará nuestra atención, sino en unas lecciones del Seminario XVIII "De un discurso que no fuera del semblante". La importancia de este seminario es, principalmente, la de posicionarse inmediatamente después del seminario ampliamente tratado en la segunda parte del artículo. Después de haber dilucidado su teoría de los cuatro discursos, Lacan se plantea la posibilidad de un discurso que no fuera del semblante. Este complejo seminario que trata de las relaciones entra hombre y mujer y de la sola Bedeutung posible, la del falo, se adentra en las diferencias entre lo escrito y la palabra, hasta llegar a su lección más significativa: la clase sobre lituraterra, que es en la que nos centraremos.

Desde el escrito La instancia de la letra en el inconsciente, o la razón después de Freud48, la letra se define como "el soporte material" 49 que el discurso toma del lenguaje. Pero es también "la estructura esencialmente localizada del significante" 50 . El significante en Lacan funciona como una marca, una huella ${ }^{51}$, éste detenta una autonomía total respecto al significado. Todo ello deriva de Freud y de los mecanismos de los sueños puestos de manifiesto en la Traumdeutung, donde las imágenes en la escritura egipcia tienen valor de significante y no de significación ${ }^{52}$. Es también cierto que Freud utiliza varias veces la metáfora de la escritura para significar que unas huellas (mnémicas) resisten a cualquier tipo de borradura. Es el caso de la ya citada obra titulada Nota sobre la "pizarra mágica", a través de la cual Freud puede metaforizar la oposición entre el sistema percepción-conciencia y el inconsciente. De ello ya tenemos un ejemplo en la Traumdeutung, donde la posibilidad de retener huellas mnémicas duraderas - pero no inalterables- se debía a dos sistemas distintitos del aparato psíquico ${ }^{53}$. Pero es en Más allá del principio de placer donde Freud, en una posición de jaque respecto al problema de la génesis de la conciencia, afirma que ésta surge en lugar de las huellas duraderas ${ }^{54}$. Este aspecto es sorprendente ya que el origen de la conciencia está ligado a una concatenación de huellas -quizás a una escritura sin descifrar-.

\footnotetext{
47 Inédito.

48 Lacan 2008, op. cit. (nota 1), pp. 461-495.

49 Ibidem, p. 463.

50 Ibidem, p. 469.

51 Ver las páginas 7 y 8 del artículo y las relativas notas.

52 Es necesario matizar: así como ocurre en la escritura jeroglífica en la que la transliteración de los jeroglíficos puede ser biconsonántica y triconsonántica (hay también un grupo que contiene más de tres sonidos consonantes), o representar exactamente lo que la figura del jeroglífico expresa, así también en la actividad onírica las imágenes pueden ser tomadas al pie de la letra o representar algo distinto a lo que son.

53 Freud S., Obras completas vol. V, Buenos Aires, Amorrortu editores, 1979, p. 533

54 Freud S., Obras completas vol. XVIII, Buenos Aires, Amorrortu editores, 1979, p. 25
} 
Lacan, respecto a la escritura y lo escrito -que, dicho sea de paso, para él coinciden 55 -, se muestra bastante tajante: la función de la escritura no es otra que la de representar palabras y, también, que se fabrica por su referirse al lenguaje. Lo de representar palabras es un claro guiño a Derrida, que reproducimos por entero:

Denunciar, como se hizo, dicha presencia como logocéntrica, denunciar la idea de la palabra inspirada, como se dice, porque de la palabra inspirada sin duda podemos reírnos, cargarle a la palabra toda la tontería en la que se extravió cierto discurso, y conducirnos hacia una mítica archiescritura, únicamente constituida, en suma, por lo que se percibe con sobrada razón como un punto ciego denunciable en todo lo que se meditó sobre la escritura - todo esto apenas constituye un progreso. Nunca se habla sino de otra cosa para hablar de la cosa.

Lo que yo por mi parte indiqué en su momento sobre la palabra plena -no hay que abusar, no me lleno la boca con la palabra plena y pienso incluso que la mayoría de ustedes no me escuchó de ninguna manera valerme de ella-, lo que indiqué de la palabra plena es que ella colma -son hallazgos del lenguaje, siempre bastante lindos- ella cumple la función de l'acosa, que está en el pizarrón ${ }^{56}$. Dicho de otro modo, la palabra aventaja siempre al hablador, el hablador es un hablado, que es, de todos modos, lo que enuncio desde hace tiempo 57

El otro aspecto se refiere a que no hay ninguna cuestión lógica sin la escritura, sino, por el contrario, es a partir de ésta como se constituye la lógica58. Es importante subrayar que Lacan asume con lo escrito también una relación de dependencia: es un suplemento del cual se sirve para la creación de los grafos ${ }^{59}$, y va más allá:

Ustedes comprenden bien que, si la escritura puede servir para algo, es justamente en la medida en que se distingue de la palabra - de la palabra que puede apoyarse allí. Por ejemplo, la palabra no se traduce 60

La palabra y el significante quedan relegados en el registro simbólico, mientras la escritura (y la letra) pueden indicar y representar allí donde no hay palabra: en lo real. Antes de continuar sobre esta vertiente, volvamos un momento a la función de la escritura como representación de la palabra. Lacan matiza el término "represen-

\footnotetext{
55 Lacan 2009, op. cit. (nota 13), p. 74.

56 Se refiere al grafo del deseo (Lacan J., Escritos II, Buenos Aires, Siglo Veintiuno Editores, 2008, p. 788).

57 Lacan 2009, op. cit. (nota 13), p. 72.

58 Ibídem, p. 60.

${ }^{59}$ La recurrencia a los grafos en la obra de Lacan es numerosa: desde el grafo del deseo hasta los nudos borromeos (otra forma de escritura) pasando por el esquema L y los cuatro discursos entre otros.

60 Lacan 2009, op. cit. (nota 13), p. 75.
} 
tación" añadiendo que la escritura no es simple representación, lo es y a la vez es "repercusión": "Tal vez sea la representación como tal la que hace las palabras"61. La temática del suplemento se hace cada vez más evidente, un suplemento que no suple únicamente, sino que se muestra como la posibilidad misma de aquello -la palabra- que supliría. Sin querer entrar tampoco esta vez en un dialogo entre Lacan y Derrida -ya avisamos al final de la primera parte que éste no es, por límites de tiempo y espacio, el lugar adecuado-, la introducción de la temática del suplemento nos obliga a llamar en causa al teórico de la deconstrucción:

El suplemento viene en lugar de un desfallecimiento, de un no-significado o de un norepresentado, de una no-presencia. No hay ningún presente antes de él, por lo tanto no está precedido más que por sí mismo, es decir por otro suplemento62

Las repetidas referencias en nuestro artículo a la importancia de la cadena significante nos sirven para indicar que ya en esos aspectos se da una relación ambigua del psicoanalista francés con la escritura: todo ello encuentra espacio en el Seminario XVIII, cuando su autor, en un dialogo no tan velado con Derrida, "Clase sobre Lituraterra", sitúa la escritura en lo real y el significante en lo simbólico63. Como ya hemos comentado más arriba, lo real es aquello que no puede ser completamente simbolizado, que escaparía ( escribirse.

Demos un paso atrás. Lituraterra, esta invención, es un homenaje a la "cosa" japonesa, ya que fue a la vuelta de un viaje de Japón cuando Lacan escribió el texto que venimos comentando:

Esta palabra, lituraterra, que inventé es legitimada por el Ernout y Meillet. Tal vez algunos de ustedes sepan lo que es. Se trata de un diccionario de latín llamado etimológico. Busquen en lino, litura y después en lituraruis. Se aclara bien que no tiene nada que ver con littera, la letra. A mí me importa un bledo que no tenga nada que ver. Yo no me someto forzosamente a la etimología cuando me dejo llevar por ese juego de palabras con el que se hace, llegado el caso, un chiste -con el contrepet ${ }^{64}$, en este caso evidente, viniéndome a los labios y la inversión, al oído 65

Esta vez Lacan pasa por alto la etimología y se contenta con un chiste. Este escrito, - porque, aún perteneciendo a un seminario, Lituraterra fue escrito y leído

\footnotetext{
61 Ibidem, p. 84.

62 Derrida J., De la gramatología, México D. F., Siglo Veintiuno Editores, 2005, p. 382.

63 Lacan 2009, op. cit. (nota 13), p. 114.

64 Contrepet: creación de palabras o frases mediante la inversión de letras o sílabas de un conjunto escogido a fin de crear otras que suelen tener un sentido cómico o picante. La inversión aquí se da entre littérature y lituraterre. [N. de la T.]

65 Lacan 2009, op. cit, p. 105.
} 
en la clase del 12 de mayo de 1971-, quiere ser un punto y final sobre la escritura; ésta puede

[...] considerarse en lo real la erosión del significado, es decir, lo que llovió del semblante en la medida en que esto es lo que constituye el significado. La escritura no calca el significante. No se remonta allí más que para nombrarse, pero exactamente de la misma manera que ocurre con todas las cosas que nombra la batería significante después de haberlas enumerado66

Aún inscribiéndose en lo real67, la escritura -la letra- no guarda relación con el significante. Nada, Lacan es tajante al respecto, permite confundir con el significante lo que él inscribe en las formaciones del inconsciente como letras. Es más, este acercamiento entre la letra y el significante es reconducido por Lacan a la confusión del "discurso universitario", o sea como ese saber (S2) que se pone en uso desde el semblante68. Pero la cuestión va más allá de la estructura a través de la cual el "discurso universitario" toma la palabra, ya que Lacan - de un modo que no pretende ser velado- está en completo desacuerdo con la metáfora de la escritura que Freud propone en el Proyecto (1895) ${ }^{69}$ :

Si hubiera encontrado admisibles los modelos que Freud articula en un Proyecto para describir el franqueamiento, la exploración de rutas impresivas, no habría tomado la metáfora de la escritura. Y es justamente en este punto donde no encuentro admisible el Proyecto. La escritura no es la impresión, a pesar de todo el blablablá sobre el famoso Wunderblock 70

Uno de los posibles destinatarios es, sin duda, Derrida aunque éste, por sí sólo, advierte claramente del peligro de la metáfora de la escritura en el texto freudiano:

No basta, pues, con hablar de escritura para ser fieles a Freud, se le puede traicionar de esa manera más que nunca 71

\footnotetext{
66 Ibidem, p. 114.

67 Vid. supra p. 27.

68 Lacan 2009, op. cit., p. 110. Acerca del "discurso universitario" como el del analista (ver p. 17) no hemos hecho comentario alguno por no desviarnos demasiado de la temática principal del artículo. Digamos que en el "discurso universitario" el saber ocupa el lugar del semblante que está orientado, a la vez, por el significante amo, convirtiéndolo en un discurso de simulacro. Es un saber acumulado comandado por S1 (los significantes amo reconocidos por la ciencia oficial).

69 Freud S., Obras completas vol. III, Buenos Aires, Amorrortu editores, 1979.

70 Lacan 2009, op. cit., p. 110.

${ }^{71}$ Derrida J., La escritura y la diferencia, Barcelona, Editorial Anthropos, 1989, p. 290.
} 
La cuestión reside no tanto en la metáfora que Freud utiliza, la escritura, sino en aquello que quiere representar a través de ésta: el entramado de huellas en el lugar del cual surgiría la conciencia. Volvamos otra vez al texto de Derrida:

Láminas originarias. Todo empieza con la reproducción. Ya desde siempre, es decir, depósitos de un sentido que no ha estado nunca presente, cuyo presente significado es siempre reconstituido con retardo, nachträglich, a destiempo, suplementariamente: nachträglich quiere decir también suplementario. La apelación al suplemento es aquí originaria y socava lo que se reconstituye con retardo como el presente. El suplemento, lo que parece añadirse como lo lleno a lo lleno, es también lo que suple ${ }^{72}$

Lacan, al menos aparentemente, no entra en la lógica del suplemento, pero sí afirma que no es el signo lo que da apoyo al significante, sino la letra y añade

Pero como cualquier otra cosa, según la ley de la metáfora, que, como recordé últimamente, constituye la esencia del lenguaje. Siempre es en un lugar diferente de aquel donde está, a saber, respecto al discurso, que el lenguaje atrapa cualquier cosa, y entonces también la escritura, en la red del significante ${ }^{73}$

La letra como soporte material del significante entraría en la esencia del lenguaje, que es metafórica y que Lacan, quizás con otra metáfora, indica como la red del significante. No habría, pues, otra cosa que el significante (S) y la cadena del significante (S1-S2), un significante que, recordemos una vez más la fórmula, "representa el sujeto ante otro significante". Sin embargo, en palabras del mismo Lacan, la escritura en cuanto perteneciente al registro de lo real, escaparía -por lo menos en un resto que no se deja simbolizar-a la palabra. ¿Al significante también? Parecería haber una contradicción, a menos que el significante tal como lo entiende Lacan, trascienda también la palabra, lo simbólico. El significante, entonces, asumiría el carácter de huella (trace) y la cadena significante constituiría un entramado de huellas donde el sujeto quedaría marcado por un discurso que lo habla en tanto que sujeto del significante. Recordemos que también el significante amo, como la escritura, escapa a la simbolización, pero lo problemático es que mientras éste pertenece a lo simbólico, la escritura está en el registro de lo real. Aún así tienen en común un resto que escapa sin cesar (de no escribirse) al sentido.

Lo que aquí hemos tratado también de poner de manifiesto con la larga introducción y, sobretodo, con el segundo capítulo, es que el momento en que Lacan toma un giro radical en su doctrina es también la ocasión para tratar nuevamente y más a fondo la escritura. Desde el seminario de 1971 volverá sobre la cuestión en

\footnotetext{
72 Ibidem., p. 291.

73 Lacan 2009, op. cit. (nota 13), p. 116. (Traducción modificada).
} 
más ocasiones. Es el caso del Seminario acerca de Joyce de 1975-76, Le sinthome, en el que Lacan se centrará en los nudos borromeos, los tres registros (RSI) a los que se añade el sinthome que los une entre sí -el padre-, y el síntoma que agujerea lo real. Pero el nudo borromeo es, a la vez, "la escritura del nudo borromeo", ese soporte que no es sólo del significante. La escritura "viene de otra parte que del significante"74 y Lacan se interesó en ella por primera vez en el seminario inédito de La identificación, donde recupera el einziger $\mathrm{Zug}^{75}$ freudiano. En tanto que proviene de partes distintas en un discurso que aboga por la primacía del significante, la escritura no puede ser más que intrusiva en tanto que otra ${ }^{76}$, pero que da soporte al significante y representa la precipitación de este:

Este nudo es apoyo para el pensamiento, pero, curiosamente, para obtener algo de él, hay que escribirlo, mientras que, sólo con pensarlo, no es fácil representárselo y verlo funcionar, ni siquiera el más simple. Este nudo, este nudo bo, conlleva que hay que escribirlo para ver cómo funciona.

Llamarlo nudo bo recuerda algo que se menciona en alguna parte en Joyce - donde en el monte Neubo ${ }^{77}$ se nos otorgó la ley. Una escritura es, pues, un hacer que da sostén al pensamiento 78

Hasta aquí, algo que no sorprende demasiado en el discurso lacaniano, ya que la escritura se presenta nuevamente como un soporte, una representación tal y como se vislumbró en el Seminario XVIII. Pero lo que sigue es:

A decir verdad el nudo bo cambia completamente el sentido de la escritura. Confiere a dicha escritura una autonomía, tanto más notable cuanto que hay otra escritura, esa que resulta de la que se podría llamar una precipitación del significante. En ella insistió Derrida, pero es completamente claro que yo le mostré el camino, como ya lo indica suficientemente que no he encontrado otra manera de sostener el significante más que con la escritura de S mayúscula79

No entraremos, tampoco esta vez, en las alusiones a Derrida por parte de Lacan. Sí nos parece significativo que éste, aún sosteniendo una dependencia del significante a la escritura -una escritura autónoma que resulta precisamente de la precipitación del significante-, no trate de la peligrosidad del suplemento. A ello escapa sin cesar indicando una y otra vez la distinta procedencia de significante y escritura y,

\footnotetext{
74 Lacan 2006, op. cit. (nota 24), p. 143.

$75 \mathrm{El}$ "rasgo unario".

76 Lacan 2006, op. cit. (nota 24), p. 143.

77 "Neubo" es homófono de noeud bo (nudo bo). [N. de la T.]

78 Lacan 2006, op. cit. (nota 24), p. 142.

79 Ibídem, p. 142.
} 
cómo no, desmarcándose también a través de la voz y su modulación que no queda atrapada en la escritura:

El significante es lo que queda. Pero lo que se modula en la voz no tiene nada que ver con la escritura. Es en todo caso lo que demuestra precisamente mi nudo bo, y esto cambia el sentido de la escritura. Esto muestra algo a lo que se pueden enganchar significantes. ¿Y cómo enganchamos estos significantes? Por medio de lo que llamo dit-men$\operatorname{sion}^{80}$. Lo escribo porque no estoy del todo seguro que no se les haya escapado ${ }^{81}$

Con un juego de palabras Lacan posiciona el significante en la mansión del dicho, del decir, algo que, supuestamente, escapa a la escritura. La cuestión de fondo es que Lacan quiere reducir todo al rasgo unario y para ello utiliza el soporte del nudo borromeo y el de la recta infinita (droite infinie):

¿Qué es un elemento? Un elemento es, por un lado, lo que hace uno - en otras palabras, el rasgo unario - y lo que, por hacer uno, da inicio a la sustitución. La característica de un elemento es que se proceda a la combinatoria de elementos.

Real, imaginario y simbólico bien vale la otra triada que, si se escucha la lección de Aristóteles, compone al hombre, a saber, nóus, psyché, soma, o incluso voluntad, inteligencia, afectividad 82

La larga nota al final de la segunda parte del artículo, sirvió entre otras cosas para señalar que el significante proviene del rasgo unario por sustitución 83 . ¿No se puede hablar aquí de lógica del suplemento indicada por Derrida, lógica que Lacan parece no comentar en ningún momento? Pese a sus diferencias, se podría afirmar que tanto Lacan como Derrida no se posicionan tan lejos el uno del otro como pueda parecer, lo que sería un estudio digno y necesario de emprenderse.

Para concluir, una advertencia: lo escrito hasta ahora no quiere ser más que un enfoque en la difícil tarea de definir una parte relativamente modesta de la producción lacaniana: el tema de la escritura y su función. La función, claro está, se referiría al psicoanálisis, si bien es cierto que el discurso lacaniano se presta, desde el momento que se originó -al menos en parte- desde la universidad, a un comentario y a una confrontación académica. Con ello no queremos demostrar que Lacan y sus teorías puedan ser secularizadas o, cuanto menos, esquematizadas en un marco conceptual rígido.

\footnotetext{
${ }^{80}$ Dit-mension (dicho-mención) produce en francés homofonía con dimension (dimensión) y con ditmansion (dicho mansión). Este juego de palabras proviene de otro presente en: Lacan 2009, op. cit. (nota 13) p. 26, el de la demansion (neologismo creado con el término mansion (mansión) y dimension (dimensión). [N. del T.]

${ }^{81}$ Lacan 2006, op. cit. (nota 24), p. 142.

82 Ibidem, p. 144.

83 Vid supra, nota 43.
} 